\title{
Synchromodality in the Physical Internet - dual sourcing and real-time switching between transport modes
}

\author{
Nina Lemmens ${ }^{1}$, Joren Gijsbrechts ${ }^{1}$ and Robert Boute ${ }^{1,2^{*}}$ (D)
}

\begin{abstract}
Synchromodality, also referred to as "synchronized intermodality", employs multiple transport modes in a flexible, dynamic way in order to induce a modal shift towards more environmentally friendly transport modes like rail or inland waterways, without compromising on responsiveness and quality of service. It is characterized by the synchronized parallel usage of different transport modes and/or the ability to switch freely between transport modes at particular times while a consignment is in transit. We present a decision rule that can integrate both the parallel usage, as well as real-time switching of transport modes, either in combination or separately. It takes into account real-time stock levels and service requirements of the shipper. The policy first determines at the source which volumes will be shipped using each mode of transport, and subsequently depicts whether it should switch modes at an intermediate terminal. Using a simulation study we demonstrate how our synchromodal transport policy can induce a modal shift towards low carbon transport modes.
\end{abstract}

Keywords: Synchromodality, Dual sourcing, Transport mode choice, Low carbon logistics, Physical internet, Inventory control, Simulation

\section{Introduction}

Freight transport in the future will be much different from today. Rather than being a matter of choice, it has become a necessity. Being accountable for $7-8 \%$ of the carbon emissions, freight transport is a main contributor to global warming. While most sectors have succeeded in reducing global greenhouse gas emissions over the years, transport is the only sector where emissions continue to increase. It is seen as one of the hardest economic sectors to decarbonize; partly because the demand for freight transport is expected to rise sharply over the next few decades, but also because it relies heavily on fossil fuel [1].

There are several ongoing initiatives to understand how we can transition to a low-carbon economy consistent with the internationally agreed goal of limiting global warming to well below 2 degrees Celsius. This will entail, more than any other factor, a profound transformation

*Correspondence: robert.boute@kuleuven.be

${ }^{1}$ Research Center for Operations Management, KU Leuven, Belgium ${ }^{2}$ Technology and Operations Management Area, Vlerick Business School, Ghent, Belgium through steep declines in carbon intensity across all sectors, a transition we call "deep decarbonization".

In order to substantially improve the efficiency and sustainability of logistics, [2] introduced the concept of the Physical Internet (PI). By applying concepts from Internet data transfer to real-world shipping processes, the PI exploits the concept of universal connectivity of logistics networks and services [3]. In the Physical Internet freight is moved in a similar way as data is transferred in the digital Internet: smart, seamless and making use of the network of others. Smart replenishment models will ensure freight flows are combined and synchronized efficiently, resulting in higher vehicle fill rates, a shift towards more environmentally transport modes, less trucks on the road and a significant decarbonization of freight transport.

One of the road-maps of the Physical Internet initiative is the existence of co-modal transport services within a well synchronized network, supported by corridors and hubs, providing optimal support to supply chains (see Fig. 1). It involves a step change from the current individualistic system, in which shippers and logistics service providers optimize their own networks and 


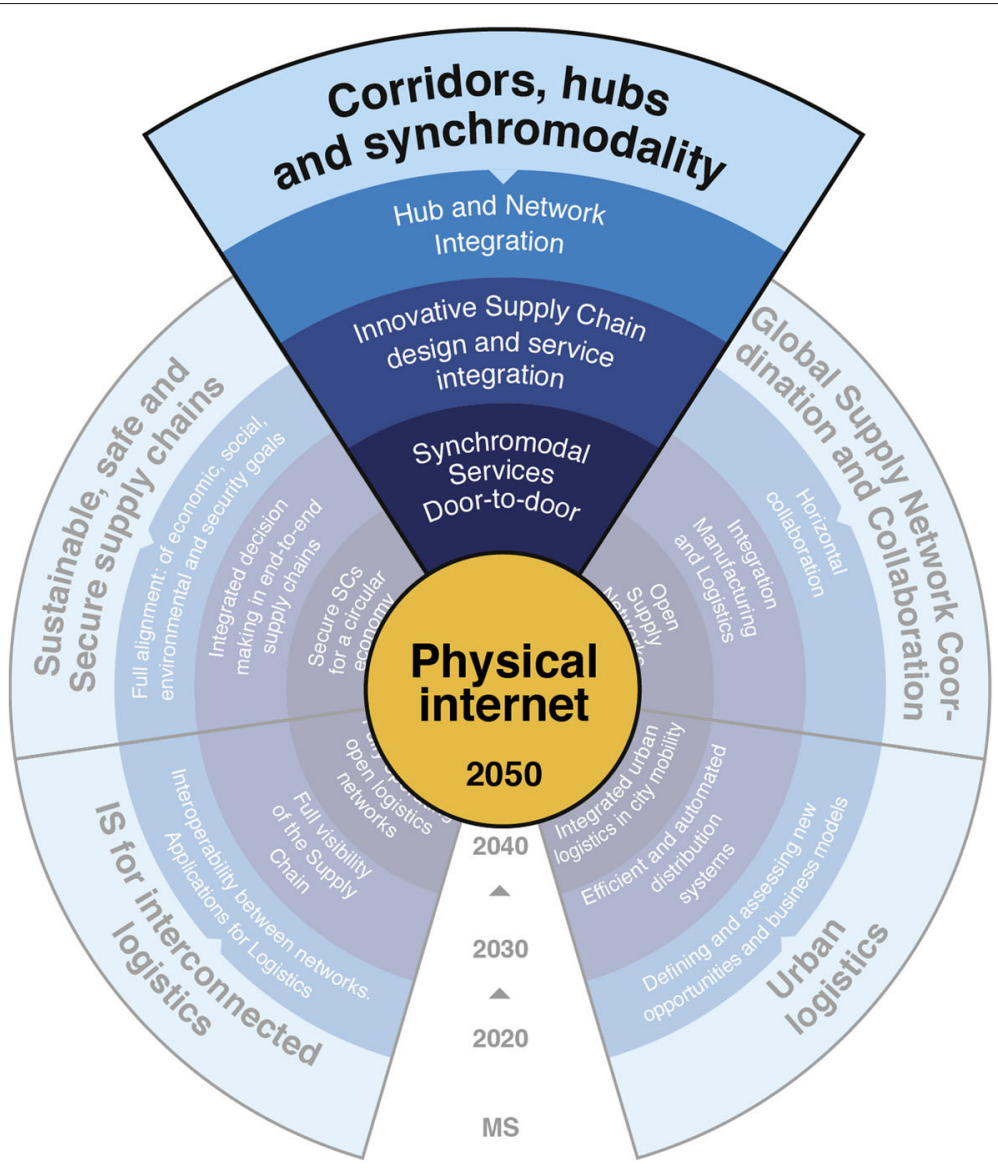

Fig. 1 Synchromodality is one of the road-maps of the Physical Internet [4]

transport flows, towards the ultimate hyperconnected Physical Internet vision, synchronizing intermodal services between modes and with shippers. This concept, referred to as Synchromodality, aligns equipment and services on corridors and hubs and proposes a transition from small individual corridors and hubs towards one hyperconnected PI system [4].

The motivation behind the greater use of intermodal transport is its superior environmental performance. According to the [5], $\mathrm{CO}_{2}$ emissions per tonne-kilometer from railways and inland waterways are about 3.5 and 5.0 times lower than those from road freight transport. Shifting freight from road to these lower carbon transport modes is therefore one of the promising ways of easing the environmental and congestion problems associated with goods movement [6].

Nonetheless, despite strenuous efforts to alter the freight modal split, most companies still rely heavily on road transport, and modal shifts to rail and water have remained modest at best. In Europe, between 1995 and 2013, road's share of total tonne-kms increased, while rail's share declined and that of inland waterways remained fairly stable [7]. The reason is that unimodal road transport is perceived to be superior when considering lead time, reliability, and flexibility of service. Vannieuwenhuyse et al. [8] interviewed 500 practitioners and find out that flexibility is indeed one of the most important criteria in their transport decision making. Although trains or barges are in general cheaper and greener, they lack flexibility in delivery quantity, frequency and scheduling [9]. As a result of this reduced flexibility, a shift from trucks to trains and barges may have an adverse impact on increased inventories or reduced service levels: As rail and inland waterway services are generally slower and less frequent than the equivalent road trips, in-transit inventories and stock levels might be higher at both ends of the journey [10]. Trains and barges also require large and stable shipment volumes in order to be cost-efficient, making it difficult for them to cater for flows that are subject to widely fluctuating demand.

To cope with the inflexibility of intermodal transport, the concept of synchromodality, or synchromodal freight transport was introduced. In one of its first explanations, 
Verweij (2011) characterized synchromodality as the ability to switch freely between transport modes at particular times while a consignment is in transit. For example, a container that was originally planned to be shipped via intermodal rail transport might be switched to direct trucking at certain terminals, for instance in case of intermodal rail delays during the first part of the journey, or in case of replenishment urgency. Or alternatively, in case the inventory at the destination is sufficiently high, intransit shipments can be slowed down. Synchromodality offers this additional flexibility to switch transport mode at several nodes on the route, while meeting cost and service level requirements [11]. This increased flexibility of synchromodal transport requires new decision rules, such as the one we introduce in this work.

Tavasszy et al. [12] describe synchromodality as synchronized intermodality: a network of well-synchronized and interconnected transport modes, which together cater for the aggregate transport demand and can dynamically adapt to the individual and instantaneous needs of network users. Synchromodality seeks to integrate different modalities to propose a "single transport service". The horizontal integration of freight transport planning allows for parallel usage of different transport modes from the origin to the destination. Freight flows on a particular route, possibly satisfying the same order, are then split between different modes. This is known as multi-mode dual sourcing. Groothedde et al. [13] and Dong et al. [10] show how this horizontal integration can be operationalized. In their case study, direct trucking and intermodal transport are synchronized in such a way that the stable part of the freight demand is carried by intermodal transport, and the variable peaks are accommodated by direct trucking.

By looking at the complementary nature of available transport modes, a synchromodal freight transport system provides a service consisting of a range of customized services with different sets of logistics requirements [12]. The objective of the increased flexibility of synchromodality is to motivate companies to shift freight from unimodal road transport to intermodal rail or waterways transport, which are more environmentally friendly.

In this paper we study how synchromodal transport can support a modal shift to slower, but more environmentally friendly transport modes without compromising on costs or responsiveness. We present a decision rule that determines how and when each of the transport modes is to be used, as a function of the dynamically evolving inventory information. The policy operates with two base-stock levels to decide at the source how to split the freight order to the different modes of transport, and then uses two threshold values to decide along the route whether a shipment should switch transport modes at an intermediate terminal. The policy is aligned with the Physical Internet vision, where smart algorithms guide freight from origin to destination.

The remainder of this paper is organized as follows. In the next section we review the main decision rules that relate to synchromodality. Section 3 introduces our model and our transport mode choice policy and in Section 4 we discuss the results from a simulation experiment that we have conducted to demonstrate the value of our policy. Section 5 concludes.

\section{Literature review}

The cornerstone of synchromodality is the integration of different modalities to provide flexibility in handling transport demand. Whereas intermodal freight transport focuses on the vertical integration of logistic services within one intermodal transport chain, the distinctive feature of synchromodality is the horizontal integration within a whole transport system [12]. Where intermodal transport comprises sequential usage of multiple transport modes, synchromodal transport permits their simultaneous usage, of which one of these modes could be an intermodal service [10].

The parallel usage of multiple transport modes is equivalent to the multi-mode dual sourcing problem. The dual sourcing problem determines how and when each of the sources is to be used, trading off the lead time and cost differences of the sources. One source is typically low cost but has long lead times (similar to intermodal transport), whereas the other provides quicker response but at a higher (environmental) price (direct trucking).

Fukuda [14] showed that a dual base-stock policy is optimal in this model, as long as the lead time difference of both sources is exactly one period. Under this policy, the size of the order to be placed with the expedited source, if any, is first determined by a base-stock policy acting on the inventory position (= the inventory level plus all outstanding orders): an order is placed iff this inventory position is below a given base stock level; when applicable, it is sized to elevate the inventory position to this base stock level. After the order with the expedited supplier is added to this inventory position, a second base-stock policy is applied to determine the order size with the slower source (if any) in a similar way. The rationale behind the dual base-stock policy is that a low inventory position (i.e., lower than the first base-stock level), requires a part of the order to be replenished urgently from the expedited supplier to avoid expensive stock-outs, despite its higher replenishment cost. When the inventory position is in between both base-stock levels, the risk of a stockout is lower; hence the replenishment order can be placed with the slower source at lower cost due to the mediocre urgency of a replenishment.

In general, lead times may differ by an arbitrary number of periods. Whittemore and Saunders [15] showed that no 
simple structure prevails when lead times differ by more than a single period and the optimal policy needs to be based on the vector of all outstanding orders. SchellerWolf [16], however, show that Fukuda's dual base-stock policy performs well with respect to the optimal policy (they provide a small-scale numerical experiment where the optimal policy can be computed using dynamic programming). Veeraraghavan and Scheller-Wolf [17] propose the use of a dual index dual base-stock policy. Here, the order to the expedited source is determined by a base-stock policy acting on the expedited inventory position, consisting of the inventory level plus all outstanding orders to arrive within the expedited supplier's lead time. The order with the slow supplier is determined by a second base-stock policy acting on the full inventory position (including all outstanding orders).

Dong et al. [18] suggest the Tailored Based Surge heuristic proposed by [19], in which a constant size order is placed with the slow transport mode and a base-stock policy is used to determine how much is shipped using the expedited road transport mode. The constant size order accommodates the lack of flexibility of intermodal transport.

Finally, [20] present an approximate dynamic program to select transport modes and transfers in a synchromodal network over a multi-period horizon. Despite the power of approximate dynamic programming, it does not reveal any insight in the decision policy itself.

\section{Model description}

We assume a stochastic periodic review inventory model with daily demand, daily replenishments and stochastic transport lead times. Daily demand is discrete and i.i.d. over time, denoted by $D^{t}$. Although demand varies over time, it does not depend on the time $t$ and we simply denote the demand by $D$ (we use this notation for all variables whose distribution does not depend on $t$, e.g. the order quantity $Q$ is not a constant, but varies over time). The unit of analysis in our model is one (intermodal) container (equivalent to 2 TEU), which implies that demand, replenishment orders and inventory levels are expressed in units of an intermodal container. Our model works for any unit of measure as long as it can be transshipped between road and intermodal rail (e.g. intermodal containers, swap bodies or $\pi$-containers in a Physical Internet setting). ${ }^{1}$

Figure 2 describes the supply chain design for which our policy is developed: transport shipments between origin (e.g., a manufacturing plant or a supplier) and destination (e.g., a warehouse) stem from the inventory replenishment at the warehouse. Replenishment orders can be shipped using two different transport modes, each with a different transport time and cost ('Mode Choice at Origin'). At an intermodal terminal along the route, these in-transit shipments can switch to a different transport mode depending on the real-time status and the urgency of the shipment: they can either be sped up or slowed down to reach the final destination ('Mode Switching at Terminal').

We denote shipments from origin to the terminal as 'upstream' shipments, and refer to shipments from terminal to destination as 'downstream' shipments. Without loss of generality we will assume that the intermodal terminal is located exactly halfway between origin and destination. $^{2}$

We assume the fast transport mode to be direct trucking and the slow transport mode intermodal rail transport. Intermodal transport is typically less flexible and tends to be slower than direct trucking. We will assume rail transport to be slightly cheaper than road transport. Although we acknowledge that the cost of rail freight transport can in some cases be similar or even higher than direct trucking (especially when only small volumes are shipped), road transport is much more detrimental for the environment and thus bears a higher environmental cost $^{3}$. We denote $c_{r}$ the variable cost to ship one container using road transport, and $c_{i}$ the variable cost of shipping one container using intermodal rail transport, with $\Delta_{c}=c_{r}-c_{i} \geq 0$ the cost difference between both transport modes.

In addition to the transport costs, a unit holding cost $h$ and unit backlog cost $b$ is incurred per period for each unit in inventory, resp. backlogged, measured by the inventory on hand $I$.

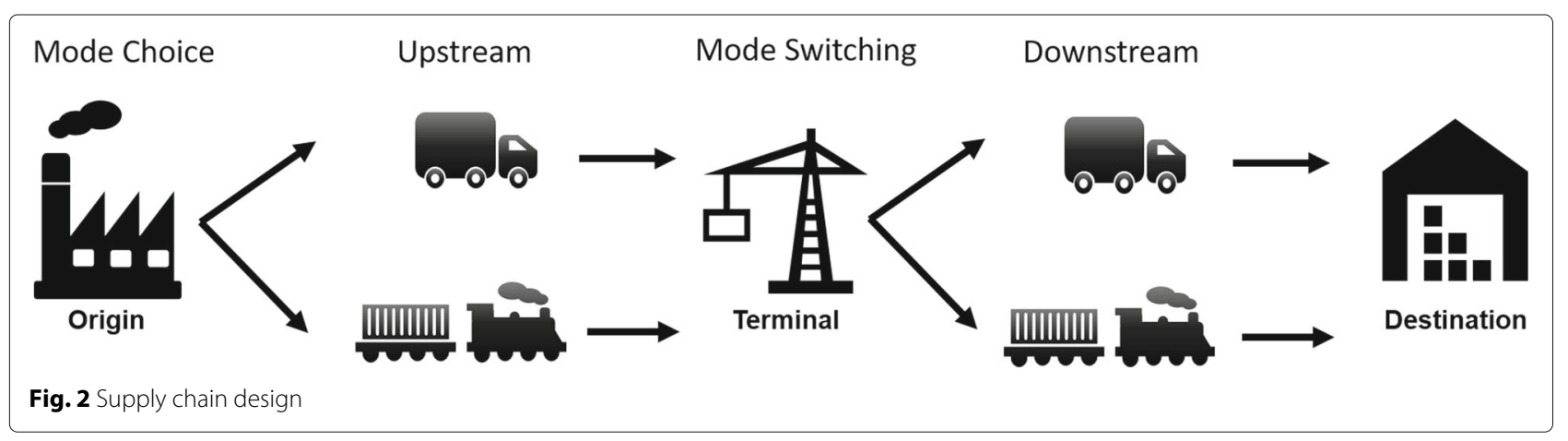


Inventory is reviewed daily. Transport times $L$ between origin and terminal, and between terminal and destination, are assumed to be stochastic. We denote $\bar{L}_{r}$ the average shipment time using road transport and $\bar{L}_{i}$ the average shipment time using intermodal transport between origin and terminal ${ }^{4}$ with $\Delta_{L}=\bar{L}_{i}-\bar{L}_{r} \geq 0$ the average lead time difference between both transport modes between origin and terminal.

We assume the following sequence of events in a period: (1) previously placed orders are received in inventory; (2) demand is satisfied from inventory (shortage is backlogged) and holding (resp. shortage) costs are incurred based on the end-of-period inventory levels; (3) replenishment orders for each transport mode are determined; and (4) upon arrival at the terminal, the decision is made whether to switch transport mode or not.

To determine how much is replenished using each transport mode (i.e., the mode choice at the origin), we use the dual base-stock policy proposed by [16] for arbitrary lead times. Denote $Q_{r}^{t}$ and $Q_{i}^{t}$ the number of units that are replenished using road, resp. intermodal rail transport in period $t$. The dual base-stock policy operates with basestock levels $S_{i} \geq S_{r}$ as follows (see Fig. 3): As long as the inventory position $I_{p}^{t}$ (inventory on hand + all outstanding orders at the beginning of period $t$ ) does not go below the higher base-stock level $S_{i}$, no replenishment orders are placed. If the inventory position is lower than $S_{i}$, but higher than the lower base-stock level $S_{r}$ (case 1), an order of $Q_{i}^{t}=S_{i}-I_{p}^{t}$ units is shipped using intermodal rail transport. If the inventory position is lower than $S_{r}$ (case 2), an order of $Q_{i}^{t}=S_{i}-S_{r}$ is shipped via intermodal rail and $Q_{r}^{t}=S_{r}-I_{p}^{t}$ units are shipped via road. In those cases, the inventory position is too low to only rely on

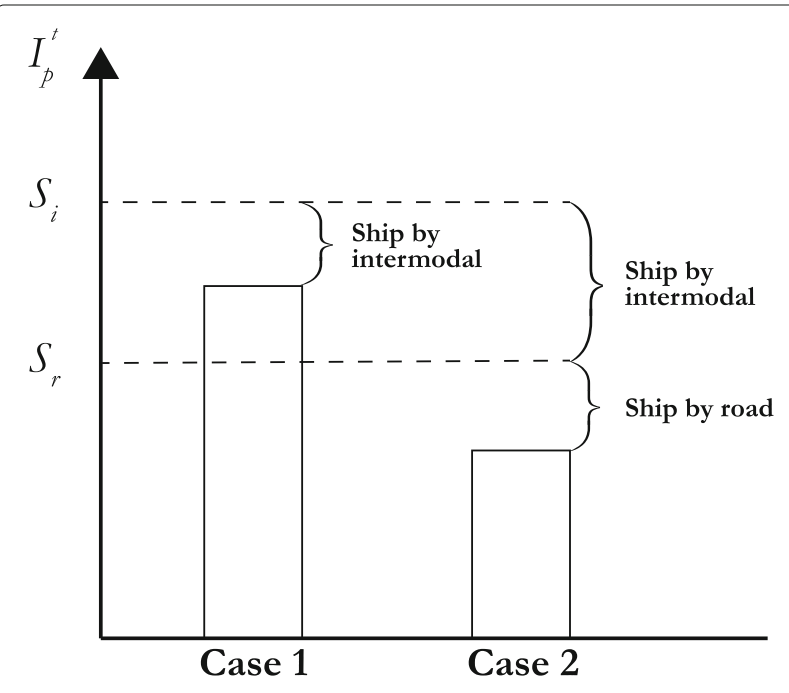

Fig. 3 When $S_{r} \leq I_{p}^{t}<S_{i}$ (case 1), only intermodal transport is used to ship $Q_{i}^{t}=S_{i}-I_{p}^{t}$ units (and $Q_{r}^{t}=0$ ); when $I_{p}^{t}<S_{r}$ (case 2), an order of $Q_{r}^{t}=S_{r}-I_{p}^{t}$ units is shipped using road transport, and $Q_{j}^{t}=S_{i}-S_{r}$ units are shipped via intermodal rail transport the slow mode. The level of the inventory position at the beginning of period $t$ thus determines the urgency of a replenishment: when the inventory is only little depleted (i.e., $S_{r} \leq I_{p}^{t}<S_{i}$ ), a slower and more sustainable transport mode can be used. If the inventory position is too low, i.e., $I_{p}^{t}<S_{r}$, a part of the replenishment should occur fast.

The values of the base-stock levels directly impact the modal split. For instance, when $S_{r}=-\infty$, we make $100 \%$ use of intermodal transport. When $S_{r}=$ $S_{i}$, we only make use of road transport. The larger the discrepancy between both base-stock levels, the higher the share of intermodal transport, and vice versa. The base-stock levels $S_{i}$ and $S_{r}$ are optimized to minimize the expected total logistics costs, consisting of transport and inventory related (i.e., holding and shortage) costs. They will eventually determine the freight modal split.

Upon arrival at the intermodal terminal, (a part of) the shipment can switch to an alternative transport mode. Each period $t$, the orders placed $L$ periods earlier, i.e., $Q_{i}^{t-L_{i}}$ and $Q_{r}^{t-L_{r}}$ arrive at the terminal. These orders can be sped up or slowed down to reach the final destination. To determine whether (a part of) the order should switch transport mode, we use a dual threshold policy that operates with threshold levels $T_{i}>T_{r}$ on the downstream inventory position. The downstream inventory position at the beginning of period $t$, which we denote by $I_{d}^{t}$, includes the inventory on hand and the inventory in transit between the terminal and the destination. The dual threshold policy works as follows (see Fig. 4): If $I_{d}^{t} \geq T_{i}$ (case 1), the replenishment is not that urgent and part of the shipment, i.e., $I_{d}^{t}-T_{i}$ units can be slowed down and switch to intermodal rail. If the order size $Q_{r}^{t-L_{r}}<I_{d}^{t}-T_{i}$, the entire shipment of $Q_{r}^{t-L_{r}}$ units proceeds the remaining journey from terminal to destination using intermodal rail. When $I_{d}^{t}<T_{r}$ (case 3 ), the replenishment becomes very urgent, and $T_{r}-I_{d}^{t}$ units are sped up by shipping the remainder of the journey via road transport. Again, if $Q_{i}^{t-L_{i}}<T_{r}-I_{d}^{t}$, the entire shipment of $Q_{i}^{t-L_{i}}$ units is switched to road transport. When $T_{r} \leq I_{d}^{t} \leq T_{i}$ (case 2), we do not make use of the switching opportunity at the terminal and the shipment continues the remaining part of the journey with the same transport mode as before.

The rationale behind this dual threshold policy to switch in-transit orders is similar to the initial dual base-stock policy: depending on the urgency of the replenishment (determined by the downstream inventory position $I_{d}^{t}$ ), the shipment should continue using a fast or rather a more sustainable mode. Also here, the threshold values directly impact the modal shift. In the extreme settings, when $T_{i}=T_{r}=+\infty$, all orders switch to road transport at the terminal, while $T_{i}=T_{r}=-\infty$ slows down all orders and switches all shipments to intermodal rail at the terminal; 


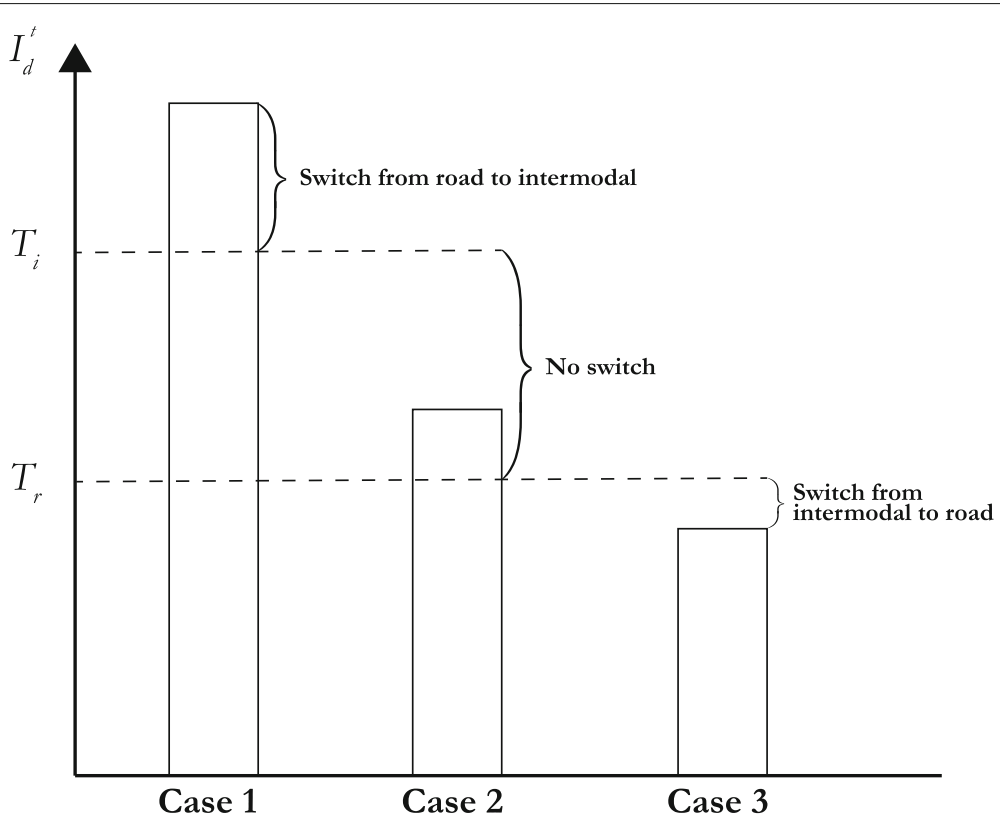

Fig. 4 When $I_{d}^{t}>T_{i}$ (case 1), $\min \left(I_{d}^{t}-T_{i}, Q_{r}^{t-L_{r}}\right.$ ) units of the order will be slowed down and shipped via intermodal transport (the shifted volume is bounded by the number of units arriving at the terminal, $Q_{r}^{t-L_{r}}$ ); when $T_{r} \leq I_{d}^{t} \leq T_{i}$ (case 2), the transport mode will remain unchanged; if $t_{d}^{t}<T_{r}$ (case 3), $\min \left(T_{r}-I_{d^{\prime}}^{t}, Q_{i}^{t-L_{i}}\right)$ units will be sped up and shipped via road transport

setting $T_{r}=-\infty$ and $T_{i}=+\infty$ results in not using the switching opportunity at all (which corresponds to the conventional dual sourcing policy of [16]). The threshold levels $T_{i}$ and $T_{r}$ are optimized to minimize the expected total logistics costs, consisting of transport and inventory related costs.

From the above it is clear that our proposed policy with the two base-stock levels and two threshold values encompasses the conventional unimodal transport (single sourcing) and dual sourcing policies. This implies among others that the long-term average cost performance of our policy will always be equally good or better than the conventional replenishment policies.

\section{Performance evaluation}

We evaluate the performance of our synchromodal policy on the logistics costs and corresponding modal shift by means of a simulation experiment. The experiment includes a sensitivity analysis on the cost, lead time and demand parameters to gain insight on the impact of different transport mode choice policies on the modal shift and corresponding costs. We hereby compare the following policies:

(1) unimodal road transport from origin to destination;

(2) unimodal road transport at the origin with the possibility to slow down (part of) the shipment at the terminal to intermodal rail transport;

(3) intermodal rail transport from origin to destination;
(4) intermodal rail transport at the origin with the possibility to speed up (part of) the shipment at the terminal to road transport;

(5) the parallel usage of road and intermodal rail transport from origin to destination, without the possibility to switch transport modes at the terminal;

(6) the combination of parallel usage of road and intermodal rail from origin to destination, with the possibility to switch a (partial) shipment to the other transport mode at the terminal.

Policy (1) uses a conventional single base-stock policy $\left(S_{i}=S_{r}\right)$, where the value of the base-stock level $S_{r}$ is optimized to minimize the long-run average logistics (transport + inventory related) costs per period, $T_{r}=-\infty$ and $T_{i}=+\infty$. Policy (2) operates under an identical single base-stock policy $\left(S_{i}=S_{r}\right)$, while now the values of $T_{i}$ and $T_{r}$ are also optimized to include the mode switching opportunity. Policy (3) relies on a single base-stock policy $\left(S_{i}\right)$ while the base-stock level $S_{r}=-\infty$, to ensure only intermodal transport is used (and $T_{r}=-\infty$ and $T_{i}=+\infty$ to exclude switching). Policy (4) is similar to policy (3), with the only difference that now the threshold values of $T_{i}$ and $T_{r}$ are also optimized. Policy (5) operates with a dual-base stock policy where the values of $S_{i}$ and $S_{r}$ are optimized to minimize the long-run average logistics costs, while $T_{r}=-\infty$ and $T_{i}=+\infty$. Finally, policy (6) operates under a dual base-stock, dual threshold policy and optimizes the values of $S_{i}, S_{r}, T_{i}$ and $T_{r}$. 
Table 1 Decision variables of our model

\begin{tabular}{ll}
\hline Decision variable Description \\
\hline$S_{r}$ & Base-stock level of road transport at the origin \\
$S_{i}$ & Base-stock level of intermodal transport at the origin \\
$T_{r}$ & Threshold value to shift volume from road to intermodal \\
$T_{i}$ & Threshold value to shift volume from intermodal to road
\end{tabular}

The base-stock and threshold levels (summarized in Table 1) that minimize the average total logistics costs are optimized using exhaustive search for each of the four policies described above. For each set of decision variables we simulate 100 times 100,000 periods, select the best performance based on total logistics cost and report the average transport, inventory and total costs ${ }^{5}$. In addition to the logistics costs, we are particularly interested in the impact of the transport mode choice policy on the share of intermodal transport.

The demand, cost and lead time parameters in our simulation experiment are inspired by a large consumer packaged goods manufacturer with an intermodal rail connection between its manufacturing plant in Western Europe and its distribution center in Eastern Europe. Data analysis over the past two years reveals that daily demand in the DC is approximately binomially distributed, $D^{t} \sim$ $B(25,0.4)$, with a mean of 10 containers per day and standard deviation 2.45 containers. The average transport time between origin and terminal using direct trucking is $\bar{L}_{r}=4$ days, whereas it takes on average $\bar{L}_{i}=7$ days using intermodal rail. Assuming the terminal to be located exactly halfway the transport corridor, unimodal road transport from origin to destination will thus take 8 days on average. Also here, we find the transport times to be close to a (shifted, i.e. strictly positive) binomial distribution. We assume the same distribution for upstream and downstream transport times of which the parameters can be found in Table 2. We assume that in case a shipment switches to another transport mode at the terminal, a transshipment time of one day is added to the lead time (which is a conservative assumption, as often containers can be switched and shipped the same day). The cost to ship one container using road transport is $€ 2100$, respectively $€ 2000$ for intermodal rail transport. Finally, the per unit daily inventory holding cost $h=€ 100$ is derived based on the actual product values of goods within one container. We set a unit backlog cost $b=$ $€ 1900$ to match with a $95 \%$ in-stock probability according to the critical fractile $\frac{b}{b+h}$. The first row of Table 2 provides an overview of the values used in the base case of our simulation experiment.

To strengthen the results and to better understand how the different transport mode choice policies operate under different circumstances, we perform a sensitivity analysis for different values of (1) deviations in the lead time of intermodal transport, for instance because of delays during shipment or capacity restrictions at the terminal (settings 1-3), (2) demand variability (settings 4-6), (3) cost differential between road and intermodal transport (settings 7-9) and (4) the unit backlog cost, impacting the target service level (settings 10-12). The parameters of each of these twelve additional settings are provided in Table 2.

Table 3 reports the results of our simulation experiment (averaged over the thirteen considered settings in Table 2). We benchmark all transport mode choice policies against unimodal road transport (which has a share of intermodal rail of $0 \%$ and a total cost index of $100 \%$ ).

We observe that although the total cost difference between unimodal road (policy 1) and intermodal rail

Table 2 Numerical parameters used in our simulation study. The numerical parameters that were altered for the sensitivity analysis are marked in bold

\begin{tabular}{|c|c|c|c|c|c|c|c|}
\hline & $c_{i}$ & $c_{r}$ & $h$ & $b$ & $L_{i}^{u}=L_{i}^{d}$ & $L_{r}^{u}=L_{r}^{d}$ & $D$ \\
\hline Base & 2000 & $+5 \%$ & 100 & 1900 & $\sim B(12,0.5)+1$ & $\sim B(6,0.5)+1$ & $\sim B(25,0.4)$ \\
\hline 1 & 2000 & $+5 \%$ & 100 & 1900 & $\sim B(8,0.75)+1$ & $\sim B(6,0.5)+1$ & $\sim B(25,0.4)$ \\
\hline 2 & 2000 & $+5 \%$ & 100 & 1900 & $\sim B(10,0.6)+1$ & $\sim B(6,0.5)+1$ & $\sim B(25,0.4)$ \\
\hline 3 & 2000 & $+5 \%$ & 100 & 1900 & $\sim B(18,0.33)+1$ & $\sim B(6,0.5)+1$ & $\sim B(25,0.4)$ \\
\hline 4 & 2000 & $+5 \%$ & 100 & 1900 & $\sim B(12,0.5)+1$ & $\sim B(6,0.5)+1$ & $\sim B(15,0.67)$ \\
\hline 5 & 2000 & $+5 \%$ & 100 & 1900 & $\sim B(12,0.5)+1$ & $\sim B(6,0.5)+1$ & $\sim B(20,0.5)$ \\
\hline 6 & 2000 & $+5 \%$ & 100 & 1900 & $\sim B(12,0.5)+1$ & $\sim B(6,0.5)+1$ & $\sim B(30,0.33)$ \\
\hline 7 & 2000 & $+2 \%$ & 100 & 1900 & $\sim B(12,0.5)+1$ & $\sim B(6,0.5)+1$ & $\sim B(25,0.4)$ \\
\hline 8 & 2000 & $+7 \%$ & 100 & 1900 & $\sim B(12,0.5)+1$ & $\sim B(6,0.5)+1$ & $\sim B(25,0.4)$ \\
\hline 9 & 2000 & $+10 \%$ & 100 & 1900 & $\sim B(12,0.5)+1$ & $\sim B(6,0.5)+1$ & $\sim B(25,0.4)$ \\
\hline 10 & 2000 & $+5 \%$ & 100 & 900 & $\sim B(12,0.5)+1$ & $\sim B(6,0.5)+1$ & $\sim B(25,0.4)$ \\
\hline 11 & 2000 & $+5 \%$ & 100 & 4900 & $\sim B(12,0.5)+1$ & $\sim B(6,0.5)+1$ & $\sim B(25,0.4)$ \\
\hline 12 & 2000 & $+5 \%$ & 100 & 9900 & $\sim B(12,0.5)+1$ & $\sim B(6,0.5)+1$ & $\sim B(25,0.4)$ \\
\hline
\end{tabular}


(policy 3) is minimal, intermodal rail inhibits substantially higher inventory costs. It is our experience that this refrains many companies from relying exclusively on intermodal rail transport. However, the possibility to slow down road transport shipments at the terminal (by shifting to intermodal, policy 2), or speed up intermodal shipments by shifting them to road transport at the terminal (policy 4) manages to dampen this inventory increase, while achieving a modal shift to intermodal transport at almost identical (even slightly lower) total cost performance. Parallel usage of both transport modes (policy 5) has a similar impact. The combination of parallel usage of both transport modes with real-time switching at an intermediate terminal (policy 6) always leads to the lowest total cost performance over all policies. This is not surprising as policy 6 encompasses policies 1-5 (see Section 3). The increased flexibility of synchromodal transport enables an increase in the share of intermodal transport, without cost increase. These results confirm that introducing flexibility through the use of synchromodal transport can shift away volume from carbon intensive transport modes such as road without hurting service levels or increasing inventory related costs.

Tables 4 and 5 report the performance of each setting individually, with Table 4 the total cost performance of each policy compared to unimodal road, and Table 5 the share of intermodal transport under each of the policies. Our observations remain robust in each of the considered settings: the option to either slow down (policy 2) or speed up (policy 4) shipments at the terminal in function of the inventory needs, or combining dual transport modes at the origin (policy 5) enables a modal shift in all cases, with modest cost reductions. The combination of having both options (policy 6) enables the largest modal shift.

The sensitivity analysis also leads to the following observations: First, as the cost of road transport increases

Table 3 Simulation results averaged over the 13 considered settings

\begin{tabular}{|c|c|c|c|c|c|}
\hline & $\begin{array}{l}\text { Transport mode } \\
\text { Choice Policy }\end{array}$ & $\begin{array}{l}\text { Share of } \\
\text { Intermodal }\end{array}$ & $\begin{array}{l}\text { Total } \\
\text { Costs }\end{array}$ & $\begin{array}{l}\text { Transport } \\
\text { Costs }\end{array}$ & $\begin{array}{l}\text { Inventory } \\
\text { Costs }\end{array}$ \\
\hline (1) & Road transport & $0 \%$ & $100 \%$ & $100 \%$ & $100 \%$ \\
\hline (2) & Slowing down & $40.3 \%$ & $98.9 \%$ & $87.6 \%$ & $110.4 \%$ \\
\hline (3) & Intermodal rail & $100 \%$ & $100.5 \%$ & $94.8 \%$ & $151.8 \%$ \\
\hline (4) & Speeding up & $71.0 \%$ & $97.6 \%$ & $96.3 \%$ & $109.6 \%$ \\
\hline (5) & $\begin{array}{l}\text { Parallel usage } \\
\text { of modes }\end{array}$ & $51.3 \%$ & $97.8 \%$ & $97.0 \%$ & $102.7 \%$ \\
\hline (6) & $\begin{array}{l}\text { Parallel usage and } \\
\text { real-time switching }\end{array}$ & $75.0 \%$ & $97.2 \%$ & $96.0 \%$ & $107.6 \%$ \\
\hline
\end{tabular}

Synchromodal transport through the parallel usage of transport modes and/or real-time switching increases the share of intermodal transport, while keeping inventory costs under control. The combination of parallel usage and real-time switching enables a significant modal shift (settings 8 and 9), or as target service levels go down (setting 10), relying solely on intermodal rail (policy 3) leads to lower total costs compared to unimodal road transport; yet, the combination of both modes (policies 5 or 6) or having the option to speed up shipments at the terminal (policy 4) is even more cost beneficial, as it enables to limit the inventory cost increases of intermodal transport. Second, we observe that speeding up at the terminal (policy 4) is generally more cost-effective compared to slowing down at the terminal (policy 2), while a larger modal shift can be achieved. Third, we observe that increasing the target service levels reduces the performance of intermodal rail transport due to the increased inventories while all other transport choice policies continue to perform better than unimodal road transport.

Whereas this reports only a selection of experiments, it does confirm the potential of synchromodal freight transport over a diverse range of settings.

\section{Conclusions}

In this paper we propose a policy that can be used to implement the concept of synchromodal freight transport. It prescribes how multiple transport modes can be employed in a flexible, dynamic way in order to induce a modal shift towards more environmentally friendly transport modes. Our policy encompasses the possibility to switch transport modes at an intermodal terminal

Table 4 Total cost performance of each policy compared to unimodal road (policy 1)

\begin{tabular}{lllllll}
\hline & \multicolumn{7}{l}{ Policy } & & & & & \\
\cline { 2 - 7 } & $(1)$ & $(2)$ & $(3)$ & $(4)$ & $(5)$ & $(6)$ \\
\hline Base & $0.0 \%$ & $-0.9 \%$ & $0.6 \%$ & $-1.8 \%$ & $-1.9 \%$ & $-2.0 \%$ \\
1 & $0.0 \%$ & $-2.2 \%$ & $-0.6 \%$ & $-2.9 \%$ & $-2.5 \%$ & $-3.4 \%$ \\
2 & $0.0 \%$ & $-1.0 \%$ & $0.4 \%$ & $-2.2 \%$ & $-2.0 \%$ & $-2.6 \%$ \\
3 & $0.0 \%$ & $-0.6 \%$ & $1.0 \%$ & $-2.2 \%$ & $-2.0 \%$ & $-2.2 \%$ \\
4 & $0.0 \%$ & $-0.5 \%$ & $1.1 \%$ & $-1.7 \%$ & $-2.0 \%$ & $-1.9 \%$ \\
5 & $0.0 \%$ & $-0.8 \%$ & $0.8 \%$ & $-2.0 \%$ & $-2.1 \%$ & $-2.2 \%$ \\
6 & $0.0 \%$ & $-0.6 \%$ & $0.6 \%$ & $-2.2 \%$ & $-2.0 \%$ & $-2.5 \%$ \\
7 & $0.0 \%$ & $0.0 \%$ & $3.4 \%$ & $-0.4 \%$ & $-0.6 \%$ & $-0.6 \%$ \\
8 & $0.0 \%$ & $-1.7 \%$ & $-1.2 \%$ & $-3.4 \%$ & $-2.9 \%$ & $-3.7 \%$ \\
9 & $0.0 \%$ & $-2.7 \%$ & $-2.8 \%$ & $-5.3 \%$ & $-4.2 \%$ & $-5.5 \%$ \\
10 & $0.0 \%$ & $-1.1 \%$ & $-0.5 \%$ & $-2.6 \%$ & $-2.4 \%$ & $-2.6 \%$ \\
11 & $0.0 \%$ & $-1.2 \%$ & $1.4 \%$ & $-2.3 \%$ & $-2.1 \%$ & $-3.6 \%$ \\
12 & $0.0 \%$ & $-0.9 \%$ & $2.3 \%$ & $-1.9 \%$ & $-1.9 \%$ & $-3.4 \%$ \\
Average & $0.0 \%$ & $-1.1 \%$ & $0.5 \%$ & $-2.4 \%$ & $-2.2 \%$ & $-2.8 \%$ \\
\hline
\end{tabular}

Settings $1-3$ consider different values of lead time variability of intermodal transport (low to high), settings 4-6 have different values of demand variability (low to high), settings 7-9 consider different cost differentials of road versus intermodal and settings 10-12 vary the target service level (90, 98 and 99\%) 
Table 5 The share of intermodal transport in the different synchromodal policies

\begin{tabular}{lllllll}
\hline & \multicolumn{7}{l}{ Policy } & & & & \\
\cline { 2 - 7 } & $(1)$ & $(2)$ & $(3)$ & $(4)$ & $(5)$ & $(6)$ \\
\hline Base & $0.0 \%$ & $43.3 \%$ & $100.0 \%$ & $80.6 \%$ & $40.0 \%$ & $86.1 \%$ \\
1 & $0.0 \%$ & $45.2 \%$ & $100.0 \%$ & $76.8 \%$ & $59.6 \%$ & $79.9 \%$ \\
2 & $0.0 \%$ & $42.3 \%$ & $100.0 \%$ & $65.3 \%$ & $59.6 \%$ & $77.7 \%$ \\
3 & $0.0 \%$ & $45.0 \%$ & $100.0 \%$ & $63.7 \%$ & $40.0 \%$ & $71.1 \%$ \\
4 & $0.0 \%$ & $45.9 \%$ & $100.0 \%$ & $57.4 \%$ & $50.0 \%$ & $78.9 \%$ \\
5 & $0.0 \%$ & $42.9 \%$ & $100.0 \%$ & $66.9 \%$ & $49.9 \%$ & $71.2 \%$ \\
6 & $0.0 \%$ & $39.8 \%$ & $100.0 \%$ & $67.2 \%$ & $49.8 \%$ & $73.5 \%$ \\
7 & $0.0 \%$ & $4.4 \%$ & $100.0 \%$ & $60.6 \%$ & $49.9 \%$ & $66.6 \%$ \\
8 & $0.0 \%$ & $43.3 \%$ & $100.0 \%$ & $78.7 \%$ & $68.8 \%$ & $78.4 \%$ \\
9 & $0.0 \%$ & $44.4 \%$ & $100.0 \%$ & $90.3 \%$ & $68.8 \%$ & $86.2 \%$ \\
10 & $0.0 \%$ & $44.7 \%$ & $100.0 \%$ & $87.7 \%$ & $50.1 \%$ & $70.7 \%$ \\
11 & $0.0 \%$ & $42.4 \%$ & $100.0 \%$ & $62.5 \%$ & $40.0 \%$ & $68.7 \%$ \\
12 & $0.0 \%$ & $39.6 \%$ & $100.0 \%$ & $65.4 \%$ & $40.1 \%$ & $65.9 \%$ \\
Average & $0.0 \%$ & $40.3 \%$ & $100.0 \%$ & $71.0 \%$ & $51.3 \%$ & $75.0 \%$ \\
\hline
\end{tabular}

Settings 1-3 consider different values of lead time variability of intermodal transport (low to high), settings 4-6 have different values of demand variability (low to high), settings 7-9 consider different cost differentials of road versus intermodal and settings 10-12 vary the target service level (90, 98 and 99\%)

between the origin and destination and/or the parallel usage of multiple transport modes to replenish inventories. The policy can be adopted in a Physical Internet concept, where smart algorithms guide freight from origin to destination in a sustainable way. In a numerical study we show how synchromodality can result in a modal shift to slower, but more environmentally friendly transport modes without compromising on costs or responsiveness. As a shift towards more environmentally transport modes is urgently needed to de-carbonize the logistics industry, the synchromodal concept is without doubt a promising avenue for the future of freight transport.

A prerequisite for synchromodal transport is the ability to freely choose which transport mode to use and to switch easily to another transport mode at the terminal. This involves access to intermodal transport infrastructure with fast and efficient transshipments. Advances in transshipment technologies will help us overcome these final barriers to implement synchromodality in practice. If the transshipment infrastructure is not available at an intermodal terminal, we recommend the parallel usage of transport modes without switching.

\section{Endnotes}

${ }^{1}$ While we observe a tendency towards more standardized flexible units such as intermodal containers (or $\pi$ containers in a Physical Internet setting), we acknowledge that the European trucking market still relies heavily on (semi)-trailers. In these scenarios, we recommend parallel usage of transport modes instead of mode switching.

${ }^{2}$ [21] examined the optimal number of expediting hubs and find that the optimal number of hubs seems to be one: even with only one single, optimally placed hub, most of the cost reduction could be realized. Furthermore, the optimal location of the hub seems to be in the middle of the corridor if the demand either has a very small or very large standard deviation; when the variability in demand is more moderate, the optimal location shifts more to the destination.

${ }^{3}$ Notice that when rail transport is both more expensive and slower than direct trucking, there would be no economic incentive at all to use a more sustainable transport mode.

${ }^{4}$ As the terminal is located halfway the corridor, the average upstream (from origin to terminal) and downstream (from terminal to destination) transport times are the same.

${ }^{5}$ Simulating 100 sample paths of 100,000 periods resulted in standard deviations within $0.05 \%$ of the reported (average) costs, corresponding to confidence intervals within three standard deviations from the reported average costs $(\mu \pm 3 \sigma)$ with more than $99.7 \%$ likelihood.

\section{Acknowledgments}

Not applicable.

Funding

Joren Gijsbrechts is funded by Flanders Innovation Entrepreneurship (VLAIO).

Availability of data and materials

Not applicable.

Authors' contributions

The work was a joint project of all three authors. All authors read and approved the final manuscript.

Competing interests

The authors declare that they have no competing interests.

\section{Publisher's Note}

Springer Nature remains neutral with regard to jurisdictional claims in published maps and institutional affiliations.

Received: 29 June 2018 Accepted: 21 February 2019

Published online: 02 April 2019

References

1. McKinnon, A. (2018). Decarbonizing Logistics: Distributing Goods in a Low Carbon World, 1st edn: Kogan Page. https://www.amazon.com/ Decarbonizing-Logistics-Distributing-Goods-Carbon/dp/0749483806.

2. Montreuil, B. (2011). Towards a Physical Internet: Meeting the Global Logistics Sustainability Grand Challenge. Logist Res, 3(2-3), 71-87. 
3. Montreuil, B., Ballot, E., Fontane, F. (2012). An open logistics interconnection model for the physical internet. IFAC Proceedings Volumes (IFAC-PapersOnline), 14(PART 1), 327-332.

4. ETP-Alice (2018). Roadmap: Corridors, Hubs and Synchromodality. http:// etp-logistics.eu. Accessed 15 June 2018.

5. European Environment Agency (2013). Specific CO2 emissions per tonne-km and per mode of transport in europe, 1995-2011. http://www. eea.europa.eu/data-and-maps/figures/specific-co2-emissions-pertonne-2. Accessed 15 June 2018.

6. McKinnon, AC. (2016). Freight transport deceleration: Its possible contribution to the decarbonisation of logistics. Transp Rev, 36(4), 418-436

7. EUROSTAT (2015). Greenhouse gas emission statistics. http://ec.europa. eu/eurostat/statistics-explained/index.php/Greenhouse_gas_emission_ statistics. Accessed 15 June 2018.

8. Vannieuwenhuyse, B., Gelders, L., Pintelon, L. (2003). An online decision support system for transportation mode choice. Logist InfManag, 16(2), 125-133.

9. Meers, D., Macharis, C., Vermeiren, T., van Lier, T. (2017). Modal choice preferences in short-distance hinterland container transport. Res Transp Bus Manag, 23, 46-53.

10. Dong, C., Boute, R., McKinnon, A., Verelst, M. (2018a). Investigating synchromodality from a supply chain perspective. Transp Res D Transp Environ, 61 (part A), 42-57.

11. Steadieseifi, M., Dellaert, NP., Nuijten, W., Van Woensel, T., Raoufi, R. (2014). Multimodal freight transportation planning: A literature review. Eur J Oper Res, 233(1), 1-15.

12. Tavasszy, LA., Behdani, B., Konings, R. (2015). Intermodality and synchromodality. http://dx.doi.org/10.2139/ssrn.2592888. Accessed 15 June 2018.

13. Groothedde, B., Ruijgrok, C., Tavasszy, L. (2005). Towards collaborative, intermodal hub networks: A case study in the fast moving consumer goods market. Transp Res E Logist Transp Rev, 41 (6), 567-583.

14. Fukuda, Y. (1964). Optimal Policies for the Inventory Problem with Negotiable Leadtime. Manag Sci, 10(4), 690-708.

15. Whittemore, AS., \& Saunders, SC. (1977). Optimal Inventory Under Stochastic Demand With Two Supply Options. J Appl Math, 32(2), 293-305.

16. Scheller-Wolf, A., Veeraraghavan, S., van Houtum, G. (2006). Effective dual sourcing with a single index policy, Working paper, Tepper School of Business, Carnegie Mellon University, Pittsburgh. http://opim.wharton. upenn.edu/ senthilv/papers/Singlelndex.pdf.

17. Veeraraghavan, S., \& Scheller-Wolf, A. (2008). Now or later: a simple policy for effective dual sourcing in capacitated systems. Oper Res, 56(4), 850-864.

18. Dong, C., Transchel, S., Hoberg, K. (2018b). An inventory control model for Modal Split Transport : A Tailored Base-Surge approach. Eur J Oper Res, 264(1), 1-17.

19. Allon, G., \& Van Mieghem, J.A. (2010). Global Dual Sourcing: Tailored Base-Surge Allocation to Near- and Offshore Production. Manag Sci, 56(1), 110-124.

20. Pérez Rivera, A., \& Mes, M. (2016). Service and Transfer Selection for Freights in a Synchromodal Network. In A. Paias, M. Ruthmair, S. VoSS (Eds.), Computational Logistics. ICCL 2016. Lecture Notes in Computer Science, 9855. Springer: Cham.

21. Mamani, H., \& Moinzadeh, K. (2014). Lead time management through expediting in a continuous review inventory system. Prod Oper Manag, 23(1), 95-109.

\section{Submit your manuscript to a SpringerOpen ${ }^{\circ}$ journal and benefit from:}

- Convenient online submission

- Rigorous peer review

- Open access: articles freely available online

- High visibility within the field

- Retaining the copyright to your article 